\title{
Aproximación a las relaciones entre Málaga y Melilla a través de los estudios malagueños (1497-1800)
}

LUIS SAROMPAS HERNANDEZ

Todos los autores de historias malagueñas nos relatan el origen de esta ciudad por la importancia que tuvo su puerto desde las épocas más remotas, tanto en el aspecto comercial como en el defensivo, con el paso de los siglos se convertiría en un punto clave para la historia militar. No obstante, surgirá una problemática con el comercio con África que será una constante histórica desde la Reconquista de la ciudad en época de los Reyes Católicos. Por su posición estratégica, sus relaciones comerciales y su constante ayuda a las plazas fuertes del norte de África, Málaga establecerá una serie de relaciones con Melilla que serán cruciales para la supervivencia de esta última (1).

LA TRANSICIÓN DE LA ÉPOCA MODERNA

Los Reyes Católicos por su cédula de 6 de julio de 1496, conceden licencia a Málaga para comerciar con el norte de Åfrica. No podemos saber exactamente cuando se revocó esa orden mandando cortar el flujo de mer- 
cancías, si bien nos dice que, por haber cesado las causas que motivaron aquella determinación se reanudaría el comercio (2).

Los verdaderos problemas empiezan a partir del momento en que los buques de la Casa de Arcos hacen presencia en el mar de Alborán tras la conquista de Melilla, la Corona autorizaba al duque de Medina Sidonia a retener el $50 \%$ del valor de las presas capturadas. A ellos se añaden las tripulaciones de Íñigo Manrique, alcaide de Málaga, como se pone de relieve en la detención y requisa de la nave de Nicoloso Catanno, en ruta Génova a Orán con un cargamento valorado en 10.000 ducados de oro. La nave es objeto de secuestro en el puerto de Málaga (3).

En Marruecos la decadencia mariní trae consigo el estancamiento de Badis (Vélez de la Gomera), donde cada dos años hacían escalas las galeazas venecianas, y de Cazaza (4). El 4 de octubre de 1504, los Reyes Católicos entregan a don Juan de Guzmán la ciudad de Cazaza y sus alrededores que estaban aún por conquistar, tras una interrupción por la muerte de la reina Isabel, el duque reúne fuerzas militares suficientes haciéndose efectiva su conquista en abril de 1506 (5).

Pedro Navarro se compromete a guardar el seguro de los convoyes venecianos siempre que éstos se abstengan de recalar en Vélez de la Gomera (6).

Al poco tiempo de la caída de Málaga en manos castellanas la reina Isabel se hace traer de Vélez de la Gomera unas perchas labradas en oro para candelabros (7).

Los genoveses Agostyn Ytalian y Martín Centurión, miembros ligures destacados en Málaga después de la conquista, llevan mercancías a tierras de allende para rescatar cautivos cristianos, por propia iniciativa o bajo orden del conde de Tendilla, capitán general del Reino de Granada (8).

Lo es también el de mercaderes toledanos que aparecen en Vélez de la Gomera (9).

Los textos nos indican las mercancías transportadas en un viaje de ida y vuelta a Vélez de la Gomera en el verano de 1502, parece ser que los alerces sólo crecían en Vélez de la Gomera y su tierra (10).

La ofensiva pirata se va extendiendo por estos años y la seguridad de los comerciantes en la zona de Vélez peligra cada vez más (11). 
Entre 1505 y 1510 se conquistan sucesivamente Mazalquivir, el Peñón sobre Vélez de la Gomera, Orán y Bujía. Para evitar que fuesen contraproducentes se les otorgó ciertos privilegios mediante la incorporación de regiones del interior, aunque esta idea casi no sería llevada a la práctica, Hernando de Zafra cuando preparaba las empresas contra Melilla, la presentaba a los Reyes como aduana de los dátiles y cueros de la Zagra, pero también como cabeza de puente para llegar al puerto de Tafilete por donde salen todos los califas que van para los reinos de Fez, Tremecén, Bujía y Algicer con el oro que traen de Zahara (12). Es significativa la frase que dirige el Rey Católico al conde Pedro Navarro en este sentido en 1510 " ... ha de ser que las cosas que nos quedaren en África, queden de manera que con lo mismo de África folgadamente se puedan sostener adelante, porque sostenerlas siempre con lo de acá, como ahora se hace, sería imposible y por tiempo se perderían y así no aprovecharán lo que agora facemos..." (13).

Todo el comercio que se hacía con el Peñón era casi exclusivamente para aprovisionarlo: trigo, bastimentos, cebada, plomo, carbón, agua (14).

En Melilla ocurre un fenómeno similar, donde destaca el envío de cal (15).

La mayoría de las veces los documentos no suelen datar el tipo de mercancías que contienen, aunque aparecen en algunos como el caso de Francisco Molina, vecino de Málaga que sale para Vélez de la Gomera y a su vuelta trae cueros, cera, ropa y otras cosas (16).

Para evitar conflictos con el vecino reino de Portugal y que se reconociese la soberanía castellana de Melilla y Cazaza, se desdeñarían proyectos de conquista en el África occidental. De esta manera se concentraría el esfuerzo en el África mediterránea, por lo que hemos de destacar que el tráfico entre Málaga y Melilla era considerable: trigo, materiales de construcción, pasajeros y "menudencias" (17).

\section{ÉPOCA DE LOS AUSTRIAS}

El monarca Carlos I había acumulado una serie de problemas como el levantamiento de los comuneros o el de los agermanados y al final el enfrentamiento con Francia. Todo esto originó un tipo de estrategia defensiva y no 
ofensiva en el Mediterráneo occidental, situación que aprovecharon los berberiscos para apoderarse del Peñón de Vélez de la Gomera en 1552. Esto afectaba a toda la zona sur ya que se obstruía el tráfico comercial (18).

Esta conquista había contribuido a que los berberiscos se atreviesen a atacar la costa valenciana llevándose numerosos cautivos (19). Ante estos hechos Málaga interviene en el aprovisionamiento de Melilla amenazada por el resurgimiento del poder berberisco (20).

La costa malagueña presentaba el problema de estar expuesta a los vientos del este, lo que hacía extremadamente peligrosa su navegación. Como muestra podemos citar en 1562 a las veintiocho galeras de don Juan de Mendoza, encargadas de patrullar y llevar provisiones a Orán, que fueron presa en el puerto de Málaga de este viento y tuvieron que dirigirse hacia la Herradura, donde sólo quedaron tres de las veintiocho galeras, muriendo de dos mil quinientos a cinco mil hombres (21).

A pesar de esto, la ciudad seguiría surtiendo a las galeras de Francisco de Mendoza que lograrían hacerse con Orán. Después de esta hazaña, en Cartagena esta flota recibió la noticia del rey para que pusiesen rumbo a Málaga, base de operaciones para tomar el Peñón de Vélez de la Gomera, expedición puesta al mando de Sancho de Leyva a causa de la enfermedad de Francisco de Mendoza, pero las tropas fallaron razón por la que los españoles tuvieron que regresar al puerto de Málaga (22).

En el año 1564 poniéndose las tropas al mando de García de Toledo que hizo movimientos de tropas desde Nápoles a Génova y luego hasta Málaga a las que antes se le habían unido galeras españolas bajo el mando de Álvaro de Bazán, y las de Andrea Doria. La flota llegó a Málaga el día 15 de agosto y partió el día 29 hacia el Peñón. Esta escuadra estaba formada de noventa a cien galeras además de carabelas, galeones y bergantines, aproximándose a un número de ciento sesenta navíos y dieciséis mil soldados. Después de dos meses, tras haber conquistado el Peñón, la flota regresaría a Málaga (23).

Málaga se encargaba de cuidar que no faltasen bastimientos de todo tipo a los presidios y a su vez cuando se producía algún ataque acudía en su ayuda. Así, en 1576, Málaga ayudaría a Melilla por el temor de que el rey de Argel pudiese provocar un ataque. Para el temor de que el rey de 
Argel pudiese provocar un ataque. Para este evento se contó con las galeras del comendador Gil de Andrade y unos dos mil hombres que Málaga reclutó entre los pueblos de Cártama, Alhaurín. Coín y Álora, mandados por el capitán Diego de Eslava (24).

Los acontecimientos militares hacían que se desviase la atención sobre la construcción de un puerto tan necesitado para Málaga. En 1603 Málaga se veía obligada a socorrer -a las plazas del norte de África, como era una de ellas el presidio del Peñón (25).

El problema que había generado una supuesta malversación de fondos en la construcción del ya mencionado puerto de Málaga responde a la estancia en esta ciudad del juez Francisco Roco Montenegro, enviado por el Real Consejo de Guerra para cobrar lo que Málaga debía, éste tras numerosas indagaciones llegaría a la conclusión de que este dinero podría haberse empleado en las levas efectuadas para los presidios del Peñón y Melilla. El puerto de Málaga era también utilizado para embarcar soldados a las campañas de Flandes. En 1628 salieron soldados que componían el tercio de don Simón de Macareña, con varias compañías, una formada en Málaga por don Ignacio de Zayas Bazán, otra en Ronda por don Lucas Navarrete y otra en Antequera por don Bernardo Santiesteban (26).

En los intervalos de estas acciones se acudía. como había sido normal, a la ayuda de las plazas españolas en el norte de África, a Melilla y al Peñón de forma frecuente (27).

\section{EL SIGLO XVIII}

Las islas de Alhucemas se conquistaron en 1673 por don Andrés Dávalos. Este pequeño archipiélago estaba compuesto de tres islas llamadas de Tierra, de Mar y Peñón de Alhucemas, dependían fundamentalmente de la Península en el abastecimiento de agua. En tres aljibes se recogía el agua de lluvia y la restante llegaba desde Málaga (28).

Se detecta una epidemia declarada que mermaría en parte a la población del Peñón entre 1743-45, posiblemente la peste bubónica. La provi- 
sión de los presidios que por cuenta de la Real Hacienda administraba los Cinco Gremios Mayores de Madrid, tenía establecida su base en Málaga contando con una Contaduría General, una Tesorería y unos almacenes. Málaga centralizaba estas actividades con dieciocho personas cuyos sueldos al año sumaban 98.390 reales (29).

Tanto a Alhucemas como al Peñón había que abastecerlos de agua potable a través del "ramo de la aguada" que pertenecía a la Maestranza de Tonelería. Poco antes de 1796 practicó una visita a Melilla don José Rebelo, oficial segundo de la Contaduría de la Provisión de Presidios y Armada de Málaga, por ello se sabe que existían tres grandes naves para guardar harina y leguminosas con una capacidad de cerca de cinco mil sacos, mientras que para vino existían cerca de 800-900 botas. La leña tenía almacén propio cubierto con unas doce o trece mil arrobas y un corral para más de quince mil. En sendos recintos, que daban cinco mil fanegas de cebada y de trece a catorce mil arrobas de paja para el ganado tenía un amplio corral con agua, dos pajares con capacidad para más de trece mil arrobas y divisiones para separar el ganado enfermo. Los establos tenían capacidad para mil quinientas cabezas de ganado menor y unas cuarenta de vacuno. La visita del señor Rebelo al Peñón de Vélez de la Gomera no tuvo un informe positivo debido a la nefasta administración como a la cantidad de mercancías almacenadas en un pequeño espacio. Debido a todo esto, faltaban raciones de carne, sobraban las de pescado o bien desaparecían doscientas arrobas de harina. Para el vino las bodegas estaban mal acondicionadas. La leña sólo tenía un corral en donde se apilaban dieciséis mil quintales expuestos continuamente al robo. El planteamiento de las cifras expuestas es dramático ya que el consumo mensual estaba cifrado en unas 7.700 arrobas, a partir de 1796 , consta que estas cantidades no se recibieron en su totalidad. Idéntico problema surge en las islas de Alhucemas, de las que existen algunos datos más. El resultado de la visita de don José Rebelo a Alhucemas indicaba una buena gestión, a excepción de dos productos, vino y leña, y ello a causa de que no había almacenamientos adecuados. Se podía almacenar un máximo de seis mil arrobas de leña, pero apenas doscientas de paja. Los corrales eran aceptables, unos ochenta carneros y cua- 
tro vacas. El abastecimiento de agua tenía los mismo problemas que el Peñón. Según los datos parece que el Peñón tuviese un sistema propio de recogida de agua de lluvia, en los ciento nueve trayectos llevados a cabo entre el 18 de octubre de 1794 y el 12 de octubre de 1796, se transportaron al Peñón y a Alhucemas un total de trescientas noventa y seis mil seiscientas setenta arrobas con un coste medio de setecientos setenta y seis reales por cada flete, el precio global de la aguada peninsular varió de precio conforme a los riesgos de embarque y traslado (30).

El estado de guerra con Inglaterra obstaculizaba estos abastecimientos contando los ingleses con el puerto de Gibraltar, los datos sobre embarcaciones perdidas son numerosos y aparecen en una "Relación de los efectos apresados por los corsarios pertenecientes a la provisión de presidios..." del año 1797 (31).

No hay duda de que la administración dependiente de los Cinco Gremios realizó un esfuerzo en acumular reservas que difícilmente podrían llegar a su destino. Por otro lado, no eran años optimistas en la Península en materia agrícola. 
1. PÉREZ DE COLOSÍA, M. I., Seminario celebrado en Melilla bajo el título Presencia española en el norte déAfrica 1991.

2. BEJARA VO ROBLES, F., "Reanudación del comercio de Málaga con África. bajo los Reyes Católicos". Correspondiente de la Academia de la Historia. En "Homenaje a Guillermo Gustavino", Asociación Nacional de Bibliotecas y Archivos, Madrid, 1974. Archivo Municipal de Málaga, Colección de Originales, volumen 1 , folio 229.

Col. Orig. vol. I. fol. 231.

MORALES GARCÍA GOYENA, L., Documentos históricos de Málaga, tomo I.

3. A.C.M. Legajo 63 cuad. 86 y 90. LÓPEZ DE COCA, "Relaciones mercantiles entre Granada y Berbería en época de los Reyes Católicos", Baética t. I. Universidad de Málaga, 1978, pp. 298 y ss.

4. VILLA-AMIL Y CASTRO, J., "Berbería en tiempos de Cisneros", Boletín de la Real Sociednd Geográfica de Marlrid, IV, 1879, p. 153.

LÓPEZ DE COCA, "Esclavos, alfaqueques y mercaderes en la frontera del mar de Alborán (1490-1516)", Hispania, $\mathrm{I}^{\circ} 139$, Madrid, 1978.

5. DOSSINAGE, J. M., La políica internacional de Fernando el Católico. Madrid, 1944, p. 140-141.

LÓPEZ DE COCA, Op. cit. También LÓPEZ BELTRÁN, Op. cit.

6. LÓPEZ BELTRÁ.V, M. T. "Notas sobre la expansión castellana en el Magrih a partir de 1492“, Baética, Universidad de Málagạ.

7. Archivo General de Simancas, Sección: Guerra Antigua, Leg. 1315, f. 14. LÓPEZ DE COCA. La tierra de Málaga a fines del siglo $X V$, Granada, 1977.

8. Pider al concejo que inspeccione sus embarques.

BEJARANO ROBLES, Op. cit., p. 433. En primavera de 1497 Agustín Ytulian prepara un viaje a Cazaza y a Vélez de la Comera con idéntico objeto.

Archivo Histórico de Protocolo de Málaga, leg. 10, 28/IV/1497 y 29/IV/1497.

LÓPEZ DE COCA, Op. cit. 4.

9. AHPM, leg. 10, f. 394, 19/V/1508 y 22/V/1508.

LÓPEZ DE COCA, Op. cit. 3.

10. JIMÉNEZ DE LA ESPADA, M.. La guerra del moro a fines del siglo $X V$, ed. revisada por $\mathrm{H}$. Sancho de Soprains, Ceuta, 1940, p. 16-17. LÓPEZ DE COCA, Op. cit. 3.

11. MENESES CARCÍA, E., "Granada y el Segundo Conde de Tendilla a comienzos del siglo XVI", Hispania 122, 1972, p. 566. LOPEZ DE: COCA, Op. cit. 3.

12. En carta del 22 de Abril de 1495 , Colección de Documentos Inéditos para la Historia de España, t. LI. p. 89. LÓPEZ DE COCA. Op. cit. 3.

13. LÓPEZ BELTRÁN, M. T., "Notas sobre la expansión castellana en el Magreb a partir de 1492”, Baética, Liniv. Málaga.

14. López beltrá́N, M. T., "El Puerto de Málaga en la transición a los tiempos madernos", Baética 2, p. 202-203, Univ. Málaga.

A.H.P. Leg. 75.14/12/1515. Pedro Laso de Vega envía un navío al Peñón con provisiones y al alcaide Antonio de Escolsar $y$ sus acompañantes.

15. LÓPEZ BELTRÁN: Op. cit. 12. A.H.P.M. Leg. 156 9/3/1527. Diego Sánchez de Badajoz envía un barco de cal para la fortaleza de Melilla.

16. LÓPEZ BELTRÁN, Op. cit. 12. A.H.P.M. Leg. $328,24 / 12 / 1551$.

17. LÓPEZ DE COCA, Op. cit. 14. También LÓPEZ BELTRÁ. Op. Op. cit.

18. FERRANDIS TORRES, M., "La política africana de Carlos V", Archivo del Instituto 
de Estudios Africanos, n". 50. Madrid, 1959 , p. 56-70.

19. IBÁN̄EZ DE IBERO, C., Carlos Vysu política mediterránea, Madrid, 1962. RODRÍGLEZ ALEMÁN, M. I.. El puerto de Málaga bajo los Atestrias, Diputación Provincial de Málaga, 1984.

20. RODRÍGUEZ ALEMÁN, Op. cit. A. M. M. Libros de Provisiones, vol. XI. f. 69-117, 20/V/1529.

21. RODRÍCUEZ ALEMÁN, Op. cit. CALERO PALACIOS M. C., Naufragio de la Armada Española en La Herradura, Granada, 1974.

22. DÍAZ DE ESCOBAR, M., Décadas malagueñas, 1560-1569. RODRÍGUEZ ALEMÁN, Op. cit.

23. DÍAZ DE ESCOBAR, M., Op. cit.

24. REGLA CAMPISTOL, I., "Los envíos de metales preciosos de España a Italia a través de la Corona de Aragón y sus relaciones con el bandolerismo pirenáico" Estudios de Historia Moderna, T. IV, Barcelona, 1954, p. 189-203.

RODRÍGLEZ ALEMÁN, Op. cit.

25. RODRÍGLEZ ALEMÁN, Op. cit.

A. M. M. fol. 135r. Cédula de Felipe III. Valladolid, a 12 de agosto de 1603.
26. Act. Capit, vol. IL, fols. 247r-248v. Cabildo del día 18 de marzo de 1628.

27. Act. Capit. vol. XILV; fol. 78. 30 de Abril de 1627; ihíd. vol. XLIII, fols. 268-269, ibíd., vol. XLV1, fols. $299-300 \ldots$ RODRÍGUEZ ALEMÁN, Op. cii.

28. ESTRADA, J., Población general de España, sus Reynos y provincias, ciudades, villas y. pueblos, islas adyacentes $y$ Presidios de Africa, Madrid, lmp. Andrés Ramírez, $2^{u}$ edic. 1768 , p. 522.

29. SANZ SAMPELAYO, J. F., "Las presidios españoles del Norte de África y su aprovisionamienta de viveres a finales del siglo XVIII", Anuario de Historia Moderna y Contemporánea, $n^{\circ} 4-5$, Granada.

30. SANZ SAMPELAYO, J. F. - Granada en el siglo XVIII.

- "Los presidios españoles del Norte de África y su aprovisionamiento en víveres a finales del siglo XVIII" en Amuario de Historia Moderna y Contemporánea, $\mathrm{n}$ "4-5, Granada.

31. SANZ SAMPELAYO..., Op. cit., Archivo Municipal de Granada, "Reales Provisiones", Granada. 